Best Practices in Researching Service-Learning at Community Colleges

Amanda Taggart

The University of Utah

Gloria Crisp

The University of Texas at San Antonio 


\section{Best Practices in Researching Service-Learning at Community Colleges}

In recent years, an increasing number of community colleges have integrated some form of service-learning into their programs or courses with the idea that such volunteerism will promote civic engagement, increase student satisfaction with their courses and college experience as a whole, and improve learning outcomes. There is a good amount of research published on service-learning programs and outcomes conducted at four-year institutions, though there is a dearth of studies available on service-learning at community colleges. Because community colleges serve a purpose unique from that of four-year colleges and universities, both in their mission and often in the students they serve, research on service-learning at community colleges should also be distinct from investigations at the four-year level.

This chapter details best practices in researching service-learning at community colleges. We begin with an overview of how to locate service-learning research inside and outside of academic journals. We then provide focus to key methodological issues to consider when reading and analyzing empirical work, including the role of theory. The chapter concludes with recommendations for community college faculty, staff, and administrators in applying research toward the development and/or evaluation of service-learning programming.

\section{Locating Service-Learning Research}

The following section provides suggestions for locating service-learning research at the community college level. Because the accessibility of published empirical work on this topic is now fairly limited, uncovering research on service-learning at community colleges entails conducting extensive literature searches on multiple education databases with several search term combinations. Databases such as Education Full Text, ERIC via EBSCO, JSTOR, Project 
Muse, and Academic Search Premier have proven to be very useful in covering a wide range of topics in education journals. Furthermore, we recommend using combinations of key words such as "service-learning," "experiential learning," "community college," "programs," "student development," and "student success" to find articles that explicitly discuss service-learning at the two-year level. However, this requires searching through hundreds of journals and many more articles, many of which are specific to certain disciplines (e.g., Journal of Correctional Education, Gerontology and Geriatrics Education). Manual reviews of articles published in commonly read and top tier higher education journals are also worthwhile. For instance, a recent search for literature on service-learning at community colleges located articles in the Community College Journal of Research and Practice, Journal of Experiential Education, Community College Review, and New Directions for Community Colleges. The reference pages of articles pertaining to service-learning should also be combed for other work pertinent to the subject. In addition, due to the relatively small number of academic journal articles published on service-learning in community colleges, we recommend considering unpublished work to inform current service-learning research. Unpublished research is often conducted as part of program evaluations at individual institutions, reported in dissertations or theses, or presented in conference format and can be found through the same kinds of database searches as those used for peer-reviewed journal articles. For example, in our synthesis of empirical work about the impact of service-learning on community college students (Taggart and Crisp 2011, 24-44), we reviewed studies that came from all of the above-named sources and found multiple articles from the Community College Journal of Research and Practice, as well as numerous dissertations and 
other papers on service-learning at the two-year level from the Dissertation Abstracts International database and the ERIC database.

Moreover, publicly accessible manuscripts may be retrieved from policy centers or other organizations and groups interested in community college students and can be found and accessed via Internet searches. In fact, the websites of these organizations are the richest source of information on service-learning in higher education. For instance, the National Service Learning Clearinghouse (http://www.servicelearning.org) aggregates and distributes data and research on service-learning, including specific information about service-learning at community colleges (http://www.servicelearning.org/topic/demographics-settings/community-colleges).

Furthermore, the American Association of Community Colleges (AACC) offers curriculum tools for service-learning education, publications on service-learning, and many links to other service-learning information, all easily located from their service-learning home page (http://www.aacc.nche.edu/Resources/aaccprograms/horizons/Pages/default.aspx). This website also details the AACC's Community Colleges Broadening Horizons through Service Learning project (1994-2012), the intent of which was to integrate quality service learning programming into the institutional climate of community colleges around the country. In addition, this website lists the colleges that participated in the project and also gives links to many of those schools' service-learning websites.

The Campus Compact Center for Community Colleges is another site filled with information and resources for those interested in service-learning (http://www.compact.org). Campus Compact is a national association dedicated exclusively to civic engagement on college campuses, including community service. Its website offers resources specific to faculty, students, 
association presidents, and service-learning staff. It also offers a book store where scholars and others can easily locate volumes on service-learning.

It is important to note that such an extensive search process as that outlined above necessitates an understanding of methodologically sound research in order to differentiate between strong empirical and non-rigorous or non-empirical work. Searches must be carefully filtered to find research that evaluates service-learning programs and experiences, as much of what has been published focuses on descriptions of various service-learning programs, suggestions for implementing service-learning in college courses or more widely on college campuses, or theoretical or opinion pieces on service-learning. As such, the subsequent portion of this chapter offers questions to contemplate when evaluating service-learning research.

\section{Issues to Consider when Reading Empirical Work}

The following section provides an overview of key methodological issues to consider when reading service-learning research. Issues are presented in the form of questions to be considered by community college administrators, faculty, and staff in analyzing empirical work. The first two questions are focused on understanding the paradigm of research that was conducted. The third, fourth, and fifth questions are presented to discern the degree to which findings from a study may be comparable to other studies and/or generalizable. The section concludes with two questions focused on analyzing the degree to which research findings are methodologically and theoretically sound.

What was the purpose of the research?

One issue to consider when reading empirical work on service-learning is the purpose, focus, and/or goals of the research. Service-learning research is produced for a variety of reasons 
that may intentionally or unintentionally influence how findings are presented and the degree to which findings may be useful. It is notable that the purpose or focus of the research is not always explicitly stated and may need to be discerned by the reader. A good amount of service-learning research is conducted with the intention of contributing to knowledge and theory (termed basic research) or to provide generalizable conclusions that are able to inform the development or implementation of service-learning programing (referred to as applied or action research) (Johnson and Christensen 2012). These forms of research are most often conducted by academic researchers and have the benefit of determining the degree to which service-learning is beneficial to constituents, in what ways, for how long, and under what conditions (Howard 2003, 1-12). A subset of applied research is conducted by program evaluators with the purpose of assessing the quality, value, or worth of a program (Johnson and Christensen 2012). Program evaluation can be defined as the process of systematically gathering data about a program to obtain information and measure program outcomes (National Service-Learning Clearinghouse 2001). Program evaluations answer specific questions about a particular program (Howard 2003, 1-12) and are not designed to provide findings and conclusions that are applicable to other service-learning programs. A smaller amount of research on service-learning can be categorized as advocacy research. Advocacy work is often financially supported, published as a form of marketing and program promotion, and highlights the strengths of a particular program. Although valuable to service-learning practice, a critical eye should be used when reading advocacy work as it rarely uses rigorous methodological designs and may overlook or exclude negative findings.

What type of research was conducted? 
A second question that readers of service-learning research should seek to understand is the type of research used by researchers and evaluators to answer research questions. A recent review identified that a combination of quantitative, qualitative, or mixed methodology paradigms are used for service-learning research conducted at the community college level (Taggart and Crisp 2011, 24-44). Quantitative research is used to measure service-learning outcomes and utilizes a variety of data collection tools such as test scores, surveys, and data maintained by the college including student grades or graduation rates (National ServiceLearning Clearinghouse 2001). Quantitative research is specifically used to assess relationships between participants' experiences and outcomes, including but not limited to cause and effect relationships. In contrast, qualitative research is used to gain a more holistic understanding of students' experiences, perceptions, and opinions of service-learning. Primary data collection tools used for this purpose include personal interviews, focus groups, or observations (National Service-Learning Clearinghouse 2001). Qualitative research is typically utilized to answer questions beginning with "how" or "why," such as how service-learning promotes civic engagement among students. A growing number of studies are using a combination of quantitative and qualitative paradigms in a single research study, commonly referred to as "mixed methods research," to assess the impact of service-learning programming. Mixed methods research has the benefit of providing multiple forms of data to warrant claims and may produce findings that are more valid than research that utilizes only quantitative or qualitative methods (Johnson and Christensen 2012). Educational Research: Quantitative, Qualitative and Mixed Approaches provides a more detailed explanation of each of the above-mentioned paradigms and their uses. 
Although there are numerous designs used in both qualitative and mixed methods research, we feel it may be worthwhile to provide more focus to methods used by quantitative researchers, as this form of research is often the most difficult to read and analyze. Quantitative research can be categorized into three primary designs including experimental, quasiexperimental, and non-experimental research (Johnson and Christensen 2012). Experimental designs (also known as randomized control trials or comparative designs) are conducted to measure whether a service-learning program "causes" an outcome where each participant has two potential outcomes: (1) the outcome he or she would experience if offered the program, known as the "treatment outcome" and (2) the outcome experienced if not offered the program. Because it is impossible to observe both potential outcomes for a participant, experimental designs compare outcomes of the treatment group with a control group, which is made up of a comparable group of students who did not participate in the program (Weiss Bloom and Brock 2013). Use of a control group allows the researcher to measure whether group differences are a product of initial differences, maturation, or participation in the service-learning experience (Hecht 2003, 107-124). Experimental designs rely on a process of random assignment of participants to the treatment or control group to ensure that the groups do not systematically vary in a way that may influence the findings (Johnson and Christensen 2012).

Although considered the "gold standard" of research, studies of service-learning are rarely able to use random assignment for educational and financial reasons (Hecht 2003, 107124). In these cases, a quasi-experimental design or non-experimental design may be used. A quasi-experimental design is a form of experimental research that does not involve random assignment and therefore makes it more difficult for the researchers to establish a treatment and 
control group that are comparable. This is problematic as non-equivalent groups introduce the possibility of differences between the treatment and control that unintentionally influence the findings (Johnson and Christensen 2012). For example, a service-learning study that uses an existing section of a sophomore level sociology class as the treatment group and a group of students enrolled in a developmental English class as the control group would introduce several differences between the groups (termed confounding variables) that may influence outcomes such as service-learning curriculum/activities, student academic preparation and motivation, etc.

A final form of quantitative research used in service-learning research, non-experimental designs (also referred to as before and after designs), gathers data about student outcomes before and after the service-learning experience to determine whether the experience was related to the change. Although this design does not measure cause and effect relationships, it is often the preferred method of service-learning evaluation work, as it is the simplest quantitative design and does not require a comparable control group (National Service-Learning Clearinghouse 2001). A common type of non-experimental research uses correlational designs, which are used to measure the relationship between two or more naturally occurring variables such as participation in service-learning and students' commitment to civic involvement (Clayton et al. 2013).

What type of service-learning was being studied?

There is growing evidence to suggest that: (1) different versions of the same program may have different outcomes; (2) a program that is effective for one group of individuals may not yield positive effects for another; and (3) a program that is effective under certain conditions/settings may not work in other contexts (Weiss Bloom and Brock 2013). As such, 
when reading and analyzing service-learning research, the readers should not assume that findings will apply to other programs, students, or contexts. To begin with, although all servicelearning requires some sort of community service, there is large variation in how the learning occurs (i.e., the treatment itself) (Howard 2003, 1-12). For example, some service-learning research involves co-curricular service-learning, which refers to learning and service outside of a formal course curriculum, whereas other studies involve academic service-learning, defined as bounding the service experience to the academic course curriculum (Howard 2003, 1-12). These two types of service-learning are likely to produce different outcomes and should not be assumed to be comparable.

Who were the participants?

Service-learning outcomes are also influenced by a variety of student characteristics that limit the relevance or generalizability of the findings to other student populations. Student characteristics that may impact service-learning outcomes include, but are not limited to, gender, prior academic experiences, quality of peer relationships, personality, motivation, beliefs, values, and cognitive ability (Waterman 2003, 73-90). This is of particular relevance when analyzing service-learning research that was not conducted specific to community college students, as, on the whole, students attending two-year colleges have different characteristics and experiences when compared to students who begin college at a four-year university. At the same time, service-learning research focused on community college students also should not be assumed to be generalizable to all community college students, as many studies focus on sub-populations of students such as developmental or ESL students. Further, outcomes may vary among individual 
students within a given study, which may or may not be examined by the researchers (Furco 2003, 13-34).

What were the setting context and program characteristics?

Along with variations in how service learning is defined and which students are involved, service-learning research is confounded by the diverse and situational nature of service-learning settings and experiences (Furco 2003, 13-34). It is impossible to standardize or control experiences students will have with service-learning because experiences are occurring in natural settings (Waterman 2003, 73-90). Additionally, service-learning may involve a diversity of activities and tasks, even within a given activity (Hecht 2003, 107-124). Further, the length and intensity of the service-learning experience varies across studies, with some experiences involving a single afternoon and others requiring a daily commitment for an extended period of time (Hecht 2003, 107-124). These variations in setting and program characteristics are expected to influence outcomes (Waterman 2003, 73-90). For example, findings from an exemplary service-learning program conducted at an exemplary college are likely to be largely a product of the community college and/or students rather than the service-learning experience (Hecht 2003, 107-124). In contrast, service-learning studies that utilize multiple sites or programs for comparative purposes are more likely to provide more generalizable findings. Therefore, attention should be given when reading service-learning research and making comparisons across studies or drawing conclusions about the relevance of findings to other contexts and programs (Furco 2003, 13-34).

How valid/trustworthy are the findings? 
Beyond understanding the type of research and the relevance of findings to other studies/programs, it is also important to consider the methodological rigor of the research being conducted when reading and analyzing service-learning research. A lot of community college service-learning research is based on self-reports by staff, faculty, students, or community partners. These measures can be meaningful and useful, but should be interpreted with caution, as self-reported data are likely to be biased and the reliability and validity may be limited (Clayton et al. 2013). Internal validity is a key measure of methodological rigor in quantitative research and service-learning research should use techniques and measures that demonstrate validity (Clayton et al. 2013). Internal validity can be defined as the ability of a study to measure a true relationship between variables (Johnson and Christensen 2012). Although the possibility and appropriateness of the strategy will vary across studies, researchers should identify and explain the strategies used to ensure the internal validity and trustworthiness of their results (Clayton et al. 2013).

Efforts to promote internal validity are especially important in cases where the servicelearning program at a community college is optional and students self-select into a servicelearning enhanced course. Self-selection is a serious methodological issue plaguing servicelearning research (Clayton et al. 2013), as students who choose to enroll in the service-learning course are likely to be systematically different (e.g., motivation, maturity) from students who do not choose to enroll in a service-learning course. In turn, these differences are likely to influence study outcomes. As such, caution should be used when interpreting findings from servicelearning studies that involve self-selection into service-learning but do not use random assignment or utilize efforts to control for initial differences between the treatment and control 
groups. Further, internal validity is enhanced when researchers collect data from a variety of sources (not just students) and include both disaggregated data (specific to individual students and programs) and aggregated (combined across students and programs) (Furco 2003, 13-34).

To what extent was the research design grounded in theory?

A final consideration when reading service-learning research is the degree to which the study design and evaluation efforts were guided by relevant theory. A theory is "a set of speculations about a phenomenon and its nature" (Clayton, et al. 2013) Theories are useful in service-learning research by identifying concepts and relating them in a way that assists both the reader and researcher in understanding, organizing, and predicting events. Additionally, theories pose answers to "why" questions, such as, "Why did the students change as a result of the service-learning experience?" Theories from a variety of disciplines including sociology, education, psychology, communication, and the cognitive sciences can contribute to the development and interpretation of service-learning research (Clayton et al. 2013). Unfortunately, the disconnect between program design and evaluation and existing developmental and learning theory makes it difficult to establish a cause and effect relationship between service-learning experiences and outcomes (Bradley 2003, 47-72). As such, attention should be paid to assessing the degree to which experiences and outcomes are clearly linked to theory when reading and analyzing service-learning research.

\section{Recommendations}

Given the methodological issues outlined above and the growth of service-learning initiatives on community college campuses, it is vitally important to increase the research knowledge base on service-learning in order to provide evidence for service-learning program 
outcomes (Howard 2003). Therefore, we conclude this chapter by offering several recommendations for community college faculty, staff, and administrators in applying research toward the development and/or evaluation of service-learning programming, as well as directions for future research and useful resources for those interested in studying service-learning.

First, it is important for those interested in researching service-learning to apply the suggestions previously outlined in this chapter to familiarize themselves with the research that has already been conducted and with what outcomes that work revealed. Consumers of research should use this existing work to inform all aspects of their research design and assessment—in other words, don't attempt to reinvent the wheel. For instance, prior research can provide scales or other assessment measures that others have used. If researchers determine that an existing instrument meets their needs, it can save them and their institutions time and money that would have been used creating and testing their own measures. Unfortunately, research articles that have been published in peer-reviewed journals often do not provide more than the name of the instrument used; dissertations are much more reliable in terms of providing the entire measurement instrument. However, there are examples of service-learning related assessment measures used in previous research. For instance, Shiarella, McCarthy, and Tucker (2000) have published an article on the development of the Community Service Attitudes Scales (CSAS), an instrument for measuring college students' attitudes about community service. Though that research instrument was not developed specifically for community college students, dissertation studies that are based at two-year campuses and provide complete copies of the measurement instruments used include modified versions of the Civic Education and Community Service evaluation questionnaire (Haines 2002), a student interview protocol to look at students' 
perceptions of their service-learning experiences (Hughes 2002), and an evaluation questionnaire to measure the extent to which students, faculty, and community partners met a service-learning program's objectives (Reed \& Pietrovito 2000).

When thinking about their own research, community college educators should consider work that has been conducted at four-year institutions, keeping in mind how their two-year programs may be similar to or different from those at the four-year level. For example, Astin and colleagues have written much about community service and service-learning, including largescale work on understanding how students learn in a service-learning course, how service experiences enhance college courses, and how faculty have integrated service into their curriculum (for one example, see Astin et al. 2000). In addition, we advise leaders to seek guidance from colleagues and others who already have been involved in implementing servicelearning programs in order to learn from both their mistakes and successes. This can be done through professional networks such as conferences or through the service-learning organization websites discussed earlier in this chapter. The National Service-Learning Clearinghouse website provides descriptions of and links to conferences that offer forums for presentations on servicelearning (http://www.servicelearning.org/instant_info/fact_sheets/he_facts/publishing_sl). Service-learning program administrators can also request information and contacts from these various organizations.

Considering the often limited resources on community college campuses, it is also important for faculty and administrators to understand where to focus their efforts. As such, it is wise to design research and assessment that seeks to understand the groups of students served by a particular institution. For instance, institutions who serve many non-traditionally aged college 
students should work to tailor their service-learning programs around the unique needs of this specific demographic. Doing so will be more beneficial to students and can bring significant new insight into how service-learning impacts different groups of students, an area in which we need more research to inform practice. There is also a need to understand the conditions under which service-learning is most effective, such as whether or not the service-learning is a requirement of students' degree programs or course grades.

Finally, we urge community college faculty and leaders to present and publish the research they conduct on service-learning so that others can learn from it. Again, the National Service-Learning Clearinghouse offers suggestions on where to look to publish work on servicelearning (http://www.servicelearning.org/instant_info/fact_sheets/he_facts/publishing_sl), including some previously mentioned in this chapter (e.g., Journal of Experiential Education). The potential for empirical research on service-learning at the community college level remains to be explored in depth and new work could provide valuable contributions to the field that would ultimately benefit students and institutions, as well as improve educational policy and practice. For those interested in furthering this work, we conclude this chapter with a description of a few resources that may prove useful in studying service-learning.

1) The Educator's Guide to Service-learning Evaluation, published by the National ServiceLearning Clearinghouse (National Service-Learning Clearinghouse 2001), provides additional information regarding data collection and analysis and serves as an excellent resource for community college faculty and staff engaged with service-learning programming and research. 
2) Studying Service-Learning, edited by Billig and Waterman (2003), expands on many of the ideas presented in this chapter including issues to consider when studying servicelearning, relevant developmental theories, and methodological considerations when reading and conducting research on service-learning.

3) The Measures of Service-Learning: Research Scales to Assess Student Experiences (Bringle et al. 2004), provides a primer on measurement theory and scales to measure a variety of service-learning outcomes including moral development and critical thinking.

4) The National Service-Learning Clearinghouse, which provides news about servicelearning and information on various service-learning resources. For example, a fact sheet titled Tools and Methods for Evaluating Service-Learning in Higher Education (Seifer et al. 2009) enumerates issues to consider when evaluating service-learning programs and links to multiple resources for evaluating service-learning. 


\section{Bibliography}

American Association of Community Colleges. 2013. "Service Learning." Accessed July 25. http://www.aacc.nche.edu/Resources/aaccprograms/horizons/Pages/default.aspx.

Astin, Alexander W., Lori J. Vogelgesang, Elaine K. Ikeda, and Jennifer A. Yee. 2000. How Service-Learning Affects Students. Los Angeles: Higher Education Research Institute, UCLA.

Billig, S., and Alan Waterman, edited 2003. Studying Service-Learning: Innovations in Education Research Methodology. Mahwah, NJ: Lawrence Erlbaum Associates, Publishers.

Bradley, Richard. 2003. "Using Developmental and Learning Theory in the Design and Evaluation of K-16 Service-learning Programs.” In Studying Service-Learning: Innovations in Education Research Methodology, edited by Shelley Billig and Alan Waterman, 47-72. Mahwah, NJ: Lawrence Erlbaum Associates, Publishers.

Bringle, Robert, Mindy Phillips, and Michael Hudson. 2004. The Measures of Service-Learning: Research Scales to Assess Student Experiences. American Psychological Association ebook. ISBN 1591470773.

Campus Compact Center for Community Colleges. 2013. Accessed July 25. http://www.compact.org.

Clayton, Patti, Robert Bringle, and Julie Hatcher. 2013. Research on Service-Learning: Conceptual Frameworks and Assessment. Sterling, VA: Stylus.

Furco, Andrew. 2003. "Issues of Definition and Program Diversity in the Study of ServiceLearning." In Studying Service-Learning: Innovations in Education Research 
Methodology, edited by Shelley Billig and Alan Waterman, 13-34. Mahwah, NJ:

Lawrence Erlbaum Associates, Publishers.

Haines, Dana Lee. 2002. “A Study of Community College Student Attitudes Related to ServiceLearning.” PhD diss., Baylor University.

Hecht, Deborah. 2003. "Issues of Research Design and Statistical Analysis.” In Studying ServiceLearning: Innovations in Education Research Methodology, edited by Shelley Billig and Alan Waterman, 107-124. Mahwah, NJ: Lawrence Erlbaum Associates, Publishers.

Howard, Jeffrey. 2003. “Service-Learning Research: Foundational Issues.” In Studying ServiceLearning: Innovations in Education Research Methodology, edited by Shelley Billig and Alan Waterman, 1-12. Mahwah, NJ: Lawrence Erlbaum Associates, Publishers.

Hughes, Alice. 2002. “A Study of Service-Learning at Virginia Highlands Community College and Mountain Empire Community College.” PhD diss., East Tennessee State University.

Johnson, Burke, and Larry Christensen. 2012. Educational Research: Quantitative, Qualitative, and Mixed Approaches. Thousand Oaks, CA: SAGE Publishers, Inc.

National Service-Learning Clearinghouse. 2013. Accessed July 25. http://www.servicelearning.org.

National Service-Learning Clearinghouse. 2001. "Educators' Guide to Service-Learning Program Evaluation.” Accessed July 25. http://www.servicelearning.org/filemanager/download/37/EvaluationToolkit.pdf.

Reed, Carol B., and James A. Pietrovito. 2000. "Evaluation of the Service-Learning Program at Mount Wachusett Community College: History, Philosophies, and Practices of Adult Education.” PhD diss., Nova Southeastern University. 
Seifer, Sarena D., Stacey Holmes, Julie L. Plaut, and Julie Elkins. 2009. “Tools and Methods for Evaluating Service-Learning in Higher Education.” Accessed July 25. http://www.servicelearning.org/instant_info/fact_sheets/he-facts/tools_methods.

Shiarella, Ann Harris, Anne M. McCarthy, and Mary L. Tucker. (2000). “Development and Construct Validity of Scores on the Community Service Attitudes Scale.” Educational Psychology and Measurement 60: 286-300.

Taggart, Amanda, and Gloria Crisp. 2011. "Service Learning at Community Colleges: Synthesis, Critique, and Recommendations for Future Research.” Journal of College Reading and Learning 42:24-44.

Waterman, Alan. 2003. "Issues Regarding the Selection of Variables for Study in the Context of the Diversity of Possible Student Outcomes of Service-Learning.” In Studying ServiceLearning: Innovations in Education Research Methodology, edited by Shelley Billig and Alan Waterman, 73-90. Mahwah, NJ: Lawrence Erlbaum Associates, Publishers. Weiss, Michael, Howard Bloom, and Thomas Brock. 2013. “A Conceptual Framework for Studying the Sources of Variation in Program Effects.” MDRC Working Paper on Research Methodology. Accessed July 25. http://www.mdrc.org/publication/conceptualframework-studying-sources/variation-program-effects. 